
\title{
FORMULATION OF NIOSOMAL GEL CONTAINING GREEN TEA EXTRACT
(CAMELLIA SINENSIS L. KUNTZE) USING THIN-LAYER HYDRATION
}

\section{ASTRID PERMATASARI ISNAN, MAHDI JUFRI*}

Department of Pharmaceutical Science, Faculty of Pharmacy, Universitas Indonesia, Depok, Indonesia. Email: mahdi.jufri@farmasi.ui.ac.id Received: 21 April 2017, Revised and Accepted: 13 July 2017

\begin{abstract}
Objective: Green tea is known as a source of antioxidants. The most abundant of these is epigallocatechin gallate, which has been shown to modulate biochemical pathways in the skin. Niosomes are an alternative to liposomal drug-vehicle systems, which have disadvantages such as cost and stability. To overcome the problem of low permeation of active substances through skin layers and to increase their stability, a topical antioxidant preparation based on niosomes was prepared.
\end{abstract}

Materials and Methods: To enhance drug stability, niosomal formulations were prepared in four different molar ratios of surfactant-to-cholesterol, that is, 3:1 (F1), 2:1 (F2), 1:1 (F3), and 0.5:1 (F4). These were prepared using the thin-layer method. The niosomal suspensions were evaluated for particle size and distribution, lamellarity, encapsulation efficiency, and zeta potential, and were then incorporated into gels using hydroxypropyl methylcellulose as the gelling agent. The niosomal gels were evaluated for organoleptic properties, pH, viscosity, stability, and antioxidant activity using 1,1-diphenyl-2-picrylhydrazyl.

Results: Results for the suspensions showed that F1 had the best encapsulation efficiency but experienced separation after 7 days.

Conclusions: Results for the niosomal gels (using F3) showed stable formulation without changes.

Keywords: Antioxidant activity, Encapsulation efficiency, Green tea extract, Niosome, stability.

(C) 2017 The Authors. Published by Innovare Academic Sciences Pvt Ltd. This is an open access article under the CCBY license (http://creativecommons org/licenses/by/4. 0/) DOI: http://dx.doi.org/10.22159/ijap.2017.v9s1.23_28

\section{INTRODUCTION}

Vesicles are colloidal particles with a concentric bilayer formed by amphiphilic molecules surrounding an aqueous compartment. These are useful carriers for delivering hydrophobic active substances that are bound to lipid bilayers and hydrophilic active substances that are encapsulated in the aqueous interior [1]. Liposomes were the first vesicle system discovered; however, they have several disadvantages, including cost and decreased stability at various pH levels. Niosomes are vesicle systems with non-ionic surfactants that can be made easily in the laboratory. Non-ionic surfactants have been shown to facilitate the transport of active substances through the skin [2]. Niosomes increase the time active substances can remain in the stratum corneum and epidermis [3], solving the problem of penetration of the active substance. In addition, niosomes may be used for the delivery of labile and sensitive active substances [4].

The skin is the largest organ of the body and is an important interface between the environment and the body's interior. It prevents dehydration, prevents penetration of harmful foreign materials and microorganisms, acts as a barrier against mechanical attacks, maintains constant body temperature, and transmits incoming stimuli. The skin is divided into three layers: The epidermis, the dermis, and the subcutaneous layer. The epidermis is the outermost part, consisting of the layered squamous epithelium. It also contains keratinocytes that produce filamentary keratin proteins as a protective barrier in combination with various lipid components. The epidermis consists of several layers: The basal layer (stratum basale), the Malpighi or spine (stratum spinosum) layer, the granular layer (stratum granulosum), and the horn layer (stratum corneum). During epidermal differentiation, changes are seen in lipid composition. Cholesterol, triglycerides, and phospholipids are found in the lower epidermal layers, while in the stratum spinosum and stratum granulosum, the lipids are packed into flat granules and include phospholipids, glycolipids, and free sterols. These polar lipids are converted back into neutral lipids in the intercellular space when the granular contents are released. The stratum corneum is rich in seramides, free sterols, and free fatty acids [5].

Because the skin is the outermost organ of the body, it is the main target of physical toxic substances, such as ultraviolet (UV) rays, and chemicals, such as xenobiotics, which can affect the skin's structure and function. In many environments, both direct oxidants and oxygen catalysts/ reactive oxygen species (ROS) may be directly or indirectly involved. ROS are believed to activate proliferation and signaling that may alter the apoptotic pathway, which may be involved in the pathogenesis of disease, including skin malignancies. The skin has a variety of mechanisms for dealing with toxic substances to eliminate their adverse effects, including potent antioxidants and oxidant-degradation systems. These defense mechanisms are very effective, but limited capacity can cause increased ROS in the skin that can encourage the development of the dermatological disease. One method of preventing or treating ROS-related diseases is to provide antioxidants to restore normal skin conditions [6].

Herbal antioxidants are skincare alternatives because of their more skin-friendly nature and relatively fewer adverse side effects, such as allergic reactions and compared to synthetic materials. The herbalbased antioxidant epigallocatechin gallate (EGCG) is one of the main polyphenols in green tea. Polyphenols are powerful antioxidants capable of counteracting $\mathrm{H}_{2} \mathrm{O}_{2}$ and superoxide anions, thereby preventing freeradical damage [7]. Topical EGCG modulates the biochemical pathways involved in the inflammatory response, cell proliferation, and the tumor-promoter response, and is also a marker of skin inflammation induced by mild UV light [8]. EGCG is soluble in water and ethanol [9], but it has low skin-penetrating ability [10]. In this study, to overcome the problem of low permeation of active substances through skin layers and to increase their stability, a topical antioxidant preparation based on niosomes was prepared. 


\section{MATERIALS AND METHODS}

\section{Materials}

Crude extract of green tea leaf (Balittro), standard EGCG (Sigma Aldrich), non-ionic surfactant (Span ${ }^{\circledR} 60$ ), cholesterol (Sigma Aldrich), dichloromethane, aqua demineralisata, hydroxypropyl methylcellulose (HPMC), glycerin, propylene glycol, methylparaben, propylparaben, citric acid, methanol pro analysis (Merck), ethanol pro analysis (Merck), uranyl acetate $0.2 \%$, and ascorbic acid.

\section{Tools}

Rotary evaporator (Hahn Shin), analytical scale (Sartorius), magnetic stirrer, $\mathrm{pH}$ meter(Eutech),UV-Visible(Vis) spectrophotometer (Shimadzu UV-1800), computer equipped with UV-Vis spectrophotometer (UVProbe), refrigerator, ultrasonicator (Kubota), hot plate, climatic chamber (Memmert), homogenizer, Zetasizer particle size analyzer (PSA) (Malvern), and transmission electron microscope (TEM) (JEOL).

\section{Methods}

First, a calibration curve of standard solution containing standard EGCG in ethanol was prepared at concentrations of $7,8,10,15,20$, and $24 \mathrm{ppm}$ to give A (absorbance) of 0.2-0.8 at $\lambda_{\max }=275 \mathrm{~nm}$ [11]. EGCG concentration in the crude extract of green tea was determined using the calibration curve.

Span 60 and cholesterol were dissolved in $50 \mathrm{ml}$ of dichloromethane, placed in a round flask, and evaporated on a rotary evaporator at $39^{\circ} \mathrm{C}$ until dichloromethane completely evaporated and dry layers were formed. The formed thin layer was fed with nitrogen gas, and then allowed to stand for $24 \mathrm{hrs}$ at room temperature before being hydrated to ensure the organic solvent was completely gone. The thin layer was then hydrated with a phosphate buffer solution of $\mathrm{pH} 5.5$ with the help of glass beads to form $20 \mathrm{~g}$ of the niosome preparation in a rotary evaporator at a temperature of $60^{\circ} \mathrm{C}[12,13]$.

HPMC, glycerin, propylene glycol, methylparaben, propylparaben, and aqua demineralisata were carefully weighed. The gel was prepared by dispersing the polymer in warm aqua demineralisata $\left(70^{\circ} \mathrm{C}\right)$ using a homogenizer at a rate of $1000 \mathrm{rpm}$. Methylparaben and propylparaben dissolved in the propylene glycol, glycerin, and $2 \%$ citric acid solution were added slowly to the polymer and aqua demineralisata mixture until the gel formed [14]. The niosome and gel-based suspensions with weight ratios of 1:1 were homogenized with homogenizer at a rate of $1000 \mathrm{rpm}$ (Table 1).

\section{Niosome characterization}

The formed niosomes were characterized based on particle size and distribution, lamellarity, encapsulation efficiency, and zeta potential. The size and distribution of the particles were determined using a PSA, lamellarity was determined using a TEM, efficiency of encapsulation was determined using a UV-Vis spectrophotometer, and zeta potential was determined using the Zetasizer [11,15-18].

The size and distribution of the particles were measured by diluting 1 drop of the niosomes diluted in $30 \mathrm{ml}$ of aquadest. The aqueous dispersion of the niosomes was then observed with a PSA.

Lamellarity was determined using a copper network to absorb the niosome particles from the suspension. They were then stained with $0.2 \%$ uranyl acetate in $\mathrm{ddH}_{2} \mathrm{O}$ for 1 minute and dried. Specimens were observed under the TEM at $80 \mathrm{kV}$.
The efficiency of encapsulation of the green tea extract was determined by calculating the amount of EGCG encapsulated in the niosomes. For this, $1 \mathrm{ml}$ of niosome was subjected to ultracentrifugation at 15,000 rpm for 60 minutes to separate the precipitate and supernatant. EGCG not absorbed in the supernatant was measured at $\lambda_{\max }=275 \mathrm{~nm}$. The efficiency of encapsulation was determined according to the equation:

$$
\text { EE }(\%)=\frac{\text { Total }_{\text {drug added }}-\text { Total }_{\text {free drug }}}{\text { Total }_{\text {drug added }}} \times 100
$$

Notes: Total $l_{\text {drug added }}$ : Amount of active substances inserted during preparation; Totalfree drug: Amount of free active substances in the supernatant.

\section{Stability test}

The ability of the vesicles to retain the active substance was determined by storing the niosomal suspension under different temperature conditions: $4 \pm 2^{\circ} \mathrm{C}$ (refrigerator), $25 \pm 2^{\circ} \mathrm{C}$ (room temperature), and $45 \pm 2^{\circ} \mathrm{C}$ (high temperature) for 12 weeks. Samples were periodically tested (every 2 weeks) for active substance content, in the manner described in the encapsulation efficiency procedure [19].

\section{Gel preparation evaluation}

Evaluation of gel preparations was carried out (Table 2), including organoleptic tests, $\mathrm{pH}$, viscosity using a Brookfield viscometer, and physical stability tests (cycling test, low temperature, room temperature, and high temperature).

\section{Antioxidant activity test with 1,1-diphenyl-2-picrylhydrazyl (DPPH)}

The DPPH solution was prepared by dissolving DPPH in methanol $(100 \mathrm{ppm})$, then $1 \mathrm{ml}$ of extracts of various concentrations in methanol $(2,4,6,8,10$, and $12 \mathrm{ppm})$ and $1 \mathrm{ml}$ of DPPH solution were homogenized and incubated in the dark. After 30 minutes, the absorbance was measured at $\lambda_{\max }$ of DPPH in methanol $(517 \mathrm{~nm})$. The DPPH test was also performed on ascorbic acid as a control with the same concentration and niosomal gel preparations at concentrations equivalent to $2,4,6,8$, 10 , and $12 \mathrm{ppm}$ of green tea extract. The ability to counteract the DPPH radicals was calculated using the following equation [20]:

$$
\text { DPPHcounteraction }(\%)=\frac{A-B}{A} \times 100
$$

Notes: A: Absorbance of blank solution $(1 \mathrm{ml}$ DPPH $100 \mathrm{ppm}+1 \mathrm{ml}$ methanol) at $\lambda$ DPPH=517 nm. B: Absorbance of ascorbic acid solution/extract/niosomal gel at $\lambda_{\max }$ DPPH $=517 \mathrm{~nm}$.

\section{RESULTS}

\section{Calibration curve}

The linear calibration curve with $\mathrm{r}=0.9995$ and linear regression equation $\mathrm{y}=0.00234+0.0263 \mathrm{x}$ was obtained, as seen in Fig. 1 .

\section{Formulation of niosomal gel}

After dehydration and ultrasonication, a light brown niosomal preparation was formed (Fig. 2). After the gel base was homogenized with niosomal suspension (using the F3 formula), the niosome gel preparation was lighter brown than the niosomal suspension (Fig. 3).

Table 1: Niosome formulations at various molar ratios (surfactant-to-cholesterol)

\begin{tabular}{lllll}
\hline Formulation & F1 (3:1) (mg) & F2 (2:1) (mg) & F3 (1:1) (mg) & F4 (0.5:1) (mg) \\
\hline Span 60 & 1128 & 752 & 376 & 188 \\
Cholesterol & 338 & 338 & 338 & 338 \\
Green tea extract & 400 & 400 & 400 & 400 \\
\hline
\end{tabular}

Weight of surfactant molecule (Span 60): $431 \mathrm{~g} / \mathrm{mol}$; weight of cholesterol molecule: $386.65 \mathrm{~g} / \mathrm{mol}$ 


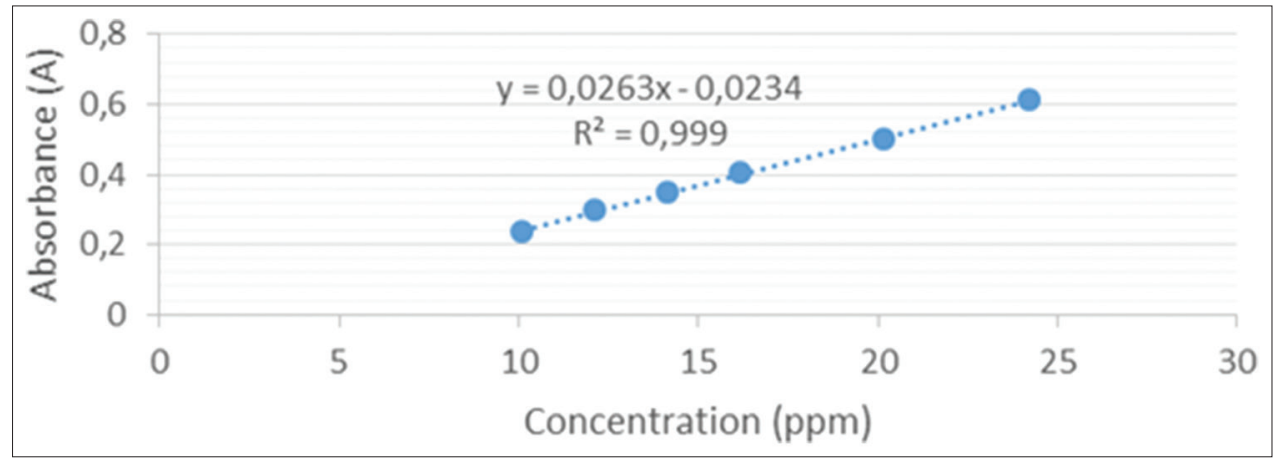

Fig. 1: Standard calibration curve of epigallocatechin gallate

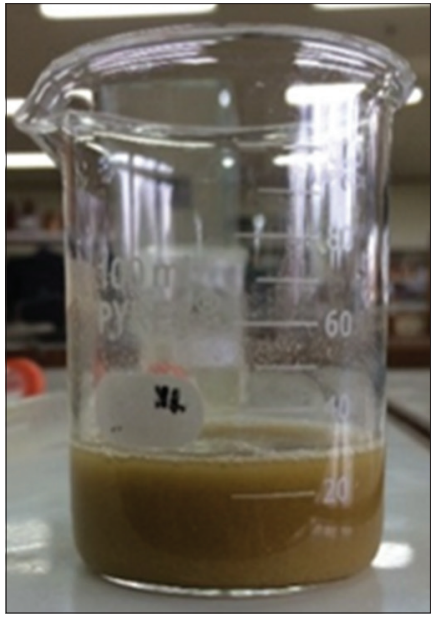

Fig. 2: Niosomal preparation containing green tea extract

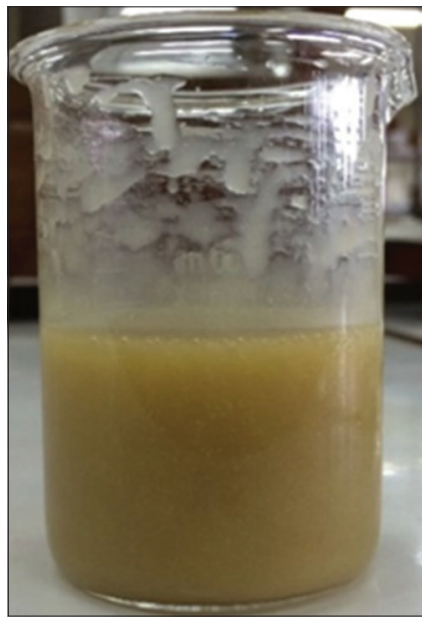

Fig. 3: Niosomal gel preparation

\section{Niosome characterization}

The size of the majority of niosomes was $338.3 \mathrm{~nm}$, and the particle distribution showed a polydispersity index of 0.349 (Fig. 4).

The TEM results showed the formation of visible vesicles. The active substance is illustrated by the black circles in the middle of the vesicles as seen in Fig. 5. The F1 encapsulation efficiency with the highest molar concentration, Span 60 , had the highest encapsulation efficiency (77.80\%) (Fig. 6 and Table 3). The niosomal suspension had a zeta potential $-40 \mathrm{mV}$ as seen in Fig. 7.

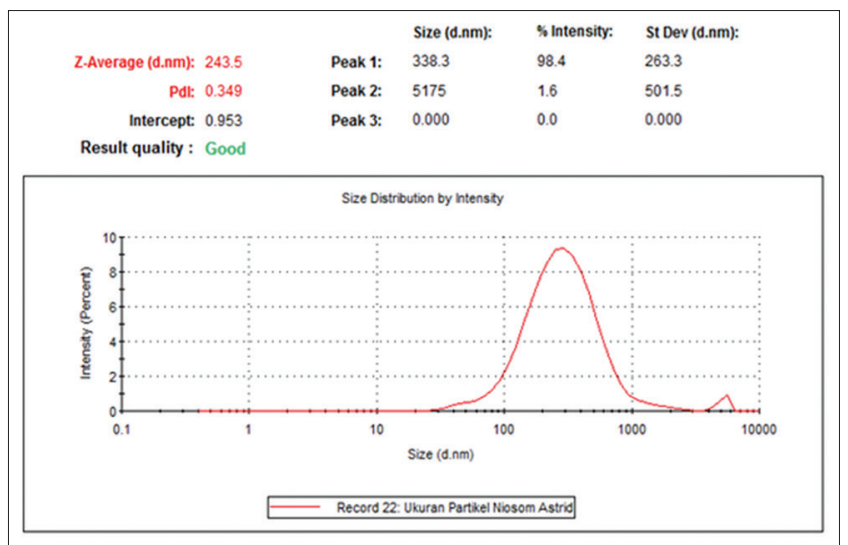

Fig. 4: Size and distribution of niosome particles

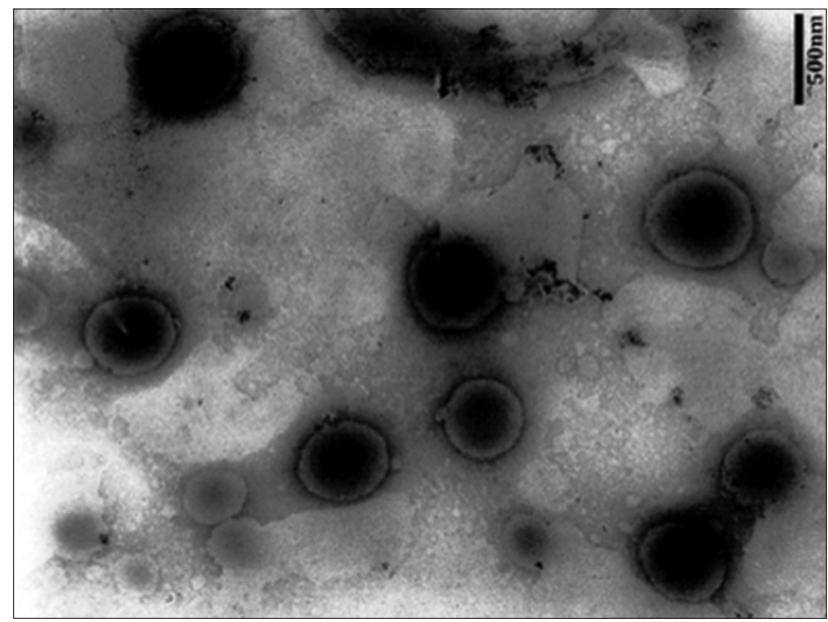

Fig. 5: Morphology of niosomes at a magnification of $\times 15,000$

\section{Niosome storage stability test}

It was shown that the niosomes were most stable when stored at a temperature of $40^{\circ} \mathrm{C}$ (Table 4). The stability testing was done using formula F3.

\section{Gel preparation evaluation}

The color of the niosomal gel that formed was light brown, distinctive, and homogeneous (Fig. 8). The pH levels formulation of F3 were 4.99, 5.00 , and 5.00, respectively. The $\mathrm{pH}$ was measured according to the $\mathrm{pH}$ range of the skin (4.5-6.5). The rheogram in Fig. 9 showed that the niosomal gel preparation was pseudoplastic. The results of the cycling test showed no changes in color or odor, and no visible syneresis. At low temperature, the niosomal gel preparation showed insignificant 


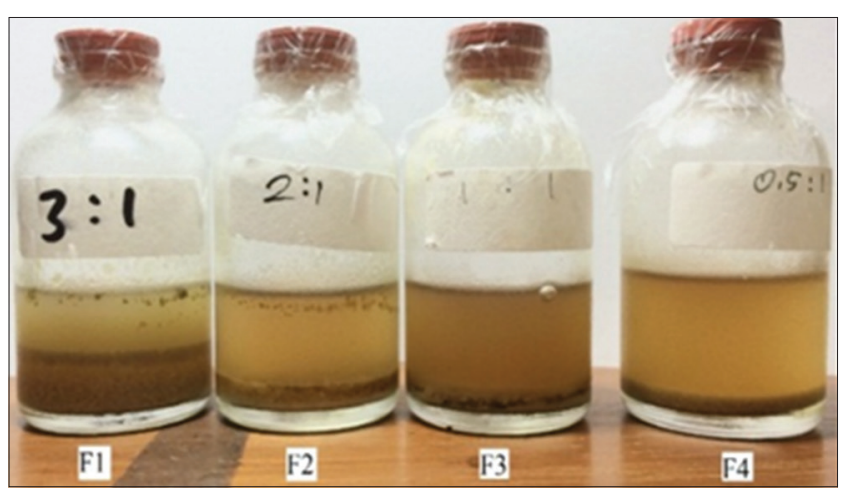

Fig. 6: Appearance of niosomal preparations of various molar concentrations

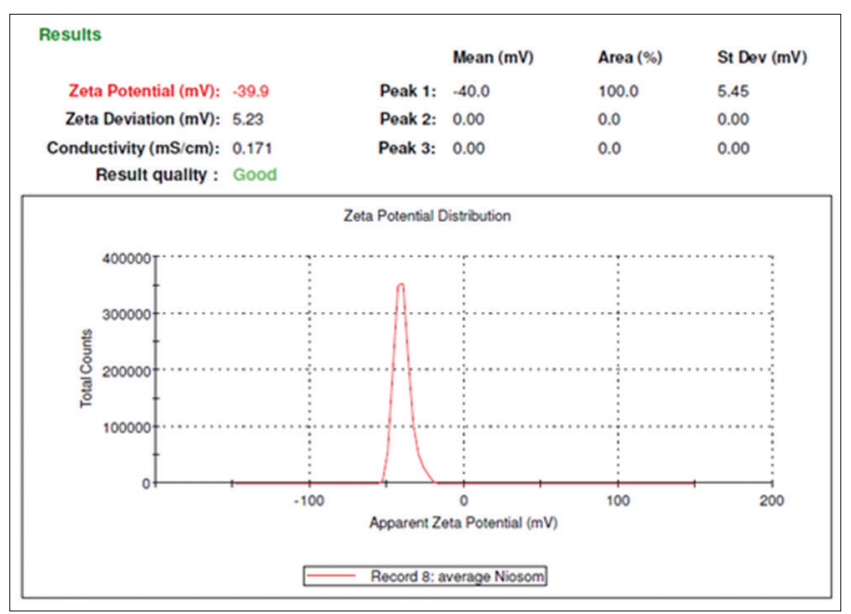

Fig. 7: Potential results of zeta niosomes

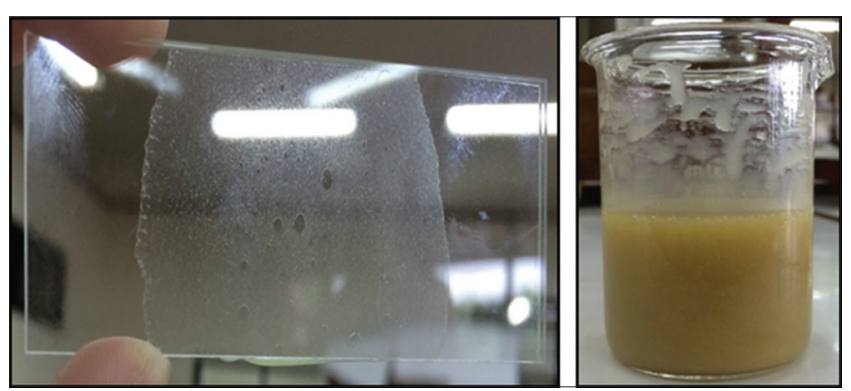

Fig. 8: Niosomal gel preparation and cell homogeneity

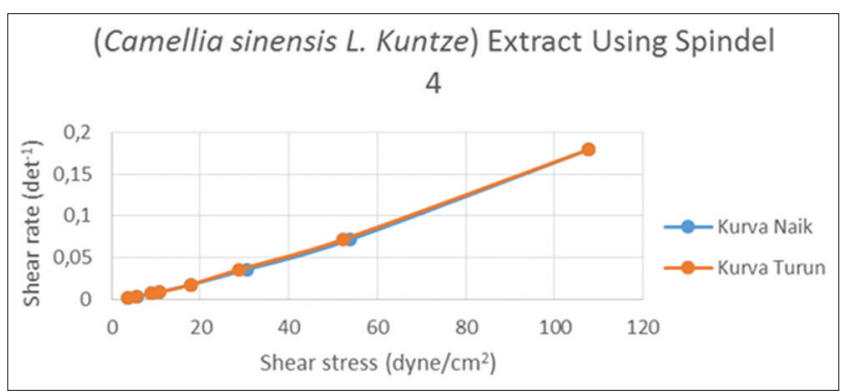

Fig. 9: Rheogram of niosomal gel with green tea extract

changes in $\mathrm{pH}$, organoleptic tests showed no changes, and the gel did not undergo syneresis (Fig. 10). At room temperature and at high
Table 2: Gel-based formulation

\begin{tabular}{ll}
\hline Material & $\mathbf{\%}(\mathbf{b} / \mathbf{b})$ \\
\hline HPMC & 10 \\
Glycerin & 10 \\
Propylene glycol & 20 \\
Methylparaben & 0.03 \\
Propylparaben & 0.01 \\
Citric acid solution 2\% (pH 5) & 4 \\
Aqua demineralisata & add 100 \\
\hline
\end{tabular}

HPMC: Hydroxypropyl methylcellulose

Table 3: Encapsulation efficiency of various niosome formulations

\begin{tabular}{ll}
\hline Formulation & Encapsulation efficiency (\%) \\
\hline Surfactant:cholesterol=3:1 & 77.80 \\
Surfactant:cholesterol=2:1 & 75.10 \\
Surfactant:cholesterol=1:1 & 63.33 \\
Surfactant:cholesterol $=0.5: 1$ & 56.39 \\
\hline
\end{tabular}

Table 4: Results of stability testing of niosomes stored at various temperatures

\begin{tabular}{lclll}
\hline Temperature $\left({ }^{\circ} \mathbf{C}\right)$ & $\begin{array}{c}\text { Week 0 } \\
(\%)\end{array}$ & $\begin{array}{c}\text { Week } \\
\mathbf{1}(\mathbf{\%})\end{array}$ & $\begin{array}{c}\text { Week } \\
\mathbf{2}(\%)\end{array}$ & $\begin{array}{c}\text { Week } \\
\mathbf{3}(\%)\end{array}$ \\
\hline 4 & 76.30 & 75.51 & 74.77 & 74.06 \\
25 & 76.30 & 74.64 & 72.94 & 71.39 \\
40 & 76.30 & 74.07 & 71.75 & 69.55 \\
\hline
\end{tabular}

temperature, $\mathrm{pH}$ level of the niosomal gel preparation decreased significantly, organoleptic tests showed no changes, and the gel did not undergo syneresis (Figs. 11 and 12).

\section{Antioxidant activity}

The DPPH test used ascorbic acid as a positive control and showed an inhibitory concentration $50 \%\left(\mathrm{IC}_{50}\right.$ ) of $8.62 \mathrm{ppm}$ for ascorbic acid. The green tea extract had an $\mathrm{IC}_{50}$ of $9.18 \mathrm{ppm}$. In the niosomal preparation and niosomal gel forms, the $\mathrm{IC}_{50}$ was slightly decreased at 11.97 and $12.51 \mathrm{ppm}$, respectively.

\section{DISCUSSION}

To manufacture the thin layer, the extract was mixed when the thin layer formed because this produces a higher absorption efficiency compared to addition of the extract during hydration. At the time of hydration, a phosphate buffer with a $\mathrm{pH}$ of 5.5 was used because the active substance of the extract is stable at acidic $\mathrm{pH}$ [21]. In the making of the gel, citric acid was added to achieve a $\mathrm{pH}$ corresponding to that of the skin (4.5-6.5).

Characterization of the niosomes showed that the resulting suspension had a uniform particle size. TEM results showed a less uniform vesicle size. This was probably due to fusion between vesicles formed during storage before the analysis. Although the results of F1 and F2 encapsulation efficiency were quite high, within 5 days of storage, F1 and F2 appeared to be separated, characterized by separation on the surface of the niosomal suspension. This was likely due to less rigid vesicles forming because the Span 60 molar ratio exceeded that of cholesterol. The zeta potential $(\leq 30 \mathrm{mV})$ indicated that the stable niosomal suspension, and the formed particles tended to resist each other, with no tendency to form aggregates.

The niosomal gel evaluation showed that the preparations were most stable when stored at low temperatures because the reaction was slowed, 


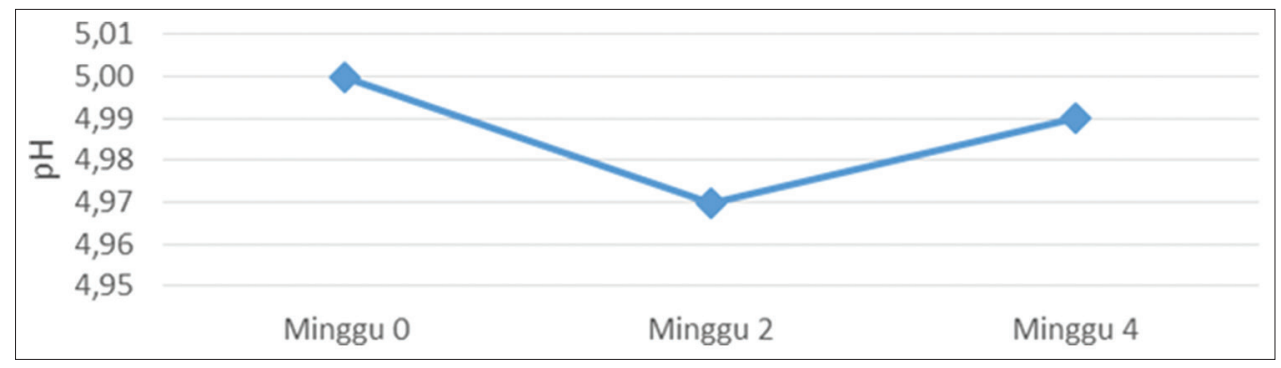

Fig. 10: Niosomal gel $\mathrm{pH}$ on low-temperature stability test $\left(4 \pm 2^{\circ} \mathrm{C}\right)$

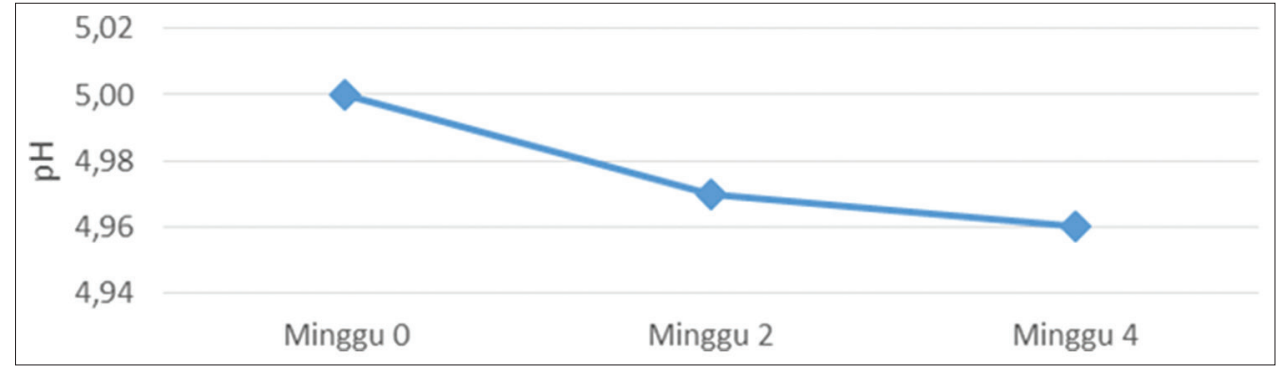

Fig. 11: Niosomal gel $\mathrm{pH}$ on room-temperature stability test $\left(25 \pm 2^{\circ} \mathrm{C}\right)$

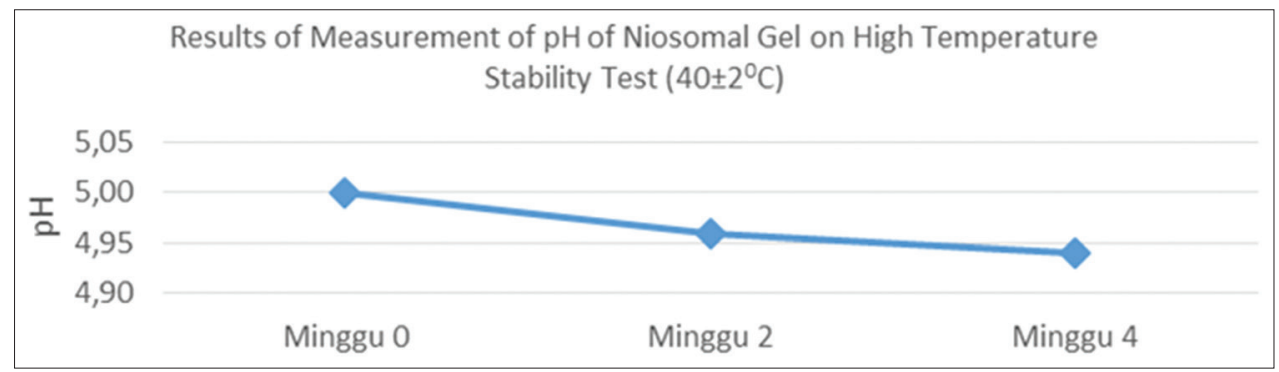

Fig. 12: Niosomal gel $\mathrm{pH}$ on high-temperature stability test $\left(40 \pm 2^{\circ} \mathrm{C}\right)$

and therefore changes were not significant. In addition, antioxidant activity was decreased as the extracts were made. This might be due to the reduced amount of free active substances of the extract due to the presence of lipid-extract complexes when dissolved in methanol.

\section{CONCLUSION}

The efficiency of niosome encapsulation containing green tea extract was increased with the greater molar concentration of Span 60. The highest encapsulation efficiency was obtained by the F1 formulation, with a molar ratio of Span 60 -to-cholesterol of 3:1, that is, $77.80 \%$. The encapsulation efficiency was $75.10 \%$ for $\mathrm{F} 2,63.33 \%$ for $\mathrm{F} 3$, and $56.39 \%$ for F4. However, F1 and F2, in which the molar ratio of Span 60 exceeded that of cholesterol, showed separation after 7 days of storage. $\mathrm{The}_{\mathrm{IC}}$ of the extract decreased as the niosomal preparation and the gel were prepared. The $\mathrm{IC}_{50}$ values for green tea extract, niosomal preparation, and niosomal gel were 9.18, 11.97, and $12.51 \mathrm{ppm}$, respectively. In addition, the niosomes with green tea extract (using formula F3) were most stable when stored at a low temperature $\left(4 \pm 2^{\circ} \mathrm{C}\right)$. We suggest adding antioxidants to niosomal preparations to improve their stability, and continuing stability testing for up to 12 weeks. The effects of hydration duration should also be studied to determine the optimum time required to achieve the desired adsorption efficiency.

\section{REFERENCES}

1. Kumar GP, Rajeshwarrao P. Nonionic surfactant vesicular systems for effective drug delivery - An overview. Acta Pharm Sin B 2011;1(4):208-19.
2. Schreier H, Bouwstra J. Liposomes and niosomes as topical drug carriers: Dermal and transdermal drug delivery. J Control Release 1994;30(1):1-15.

3. Muzzalupo R. Niosomes and proniosomes for enhanced skin delivery. In: Dragicevic N, Maibach $\mathrm{H}$, editors. Percutaneous Penetration Enhancers Chemical Methods in Penetration Enhancement. Berlin: Springer; 2016. p. 147-60.

4. Sankhyan A, Pawar P. Recent trends in niosome as vesicular drug delivery system. J Appl Pharm Sci 2012;2(6):20-32.

5. Harry R, Rieger M. Harry's Cosmeticology. New York: Chemical Publishing Co.; 2000.

6. Bickers DR, Athar M. Oxidative stress in the pathogenesis of skin disease. J Invest Dermatol 2006;126(12):2565-75.

7. Munim A, Hanani E. Fitoterapi Dasar. Jakarta: Dian Rakyat; 2011. p. $109-10$.

8. Katiyar SK, Elmets CA. Green tea polyphenolic antioxidants and skin photoprotection (review). Int J Oncol 2001;18(6):1307-13.

9. Sigma. Product Information: (-)-Epigallocatechin Gallate; 2000. Available from: http://www.sigmaaldrich.com/content/dam/sigmaaldrich/docs/Sigma/Product_Information_Sheet/e4143pis.pdf.

10. Wisuitiprot W, Somsiri A, Ingkaninan K, Waranuch N. In vitro human skin permeation and cutaneous metabolism of catechins from green tea extract and green tea extract-loaded chitosan microparticles. Int J Cosmet Sci 2011;33(6):572-9.

11. Snitsarev V, Young MN, Miller RM, Rotella DP. The spectral properties of (-)-epigallocatechin 3-O-gallate (EGCG) fluorescence in different solvents: Dependence on solvent polarity. PLoS One 2013;8(11):e79834.

12. Bakti, DR. Evaluasi dan Uji Penetrasi Formulasi Liposom yang mengandung Ekstrak Centella Asiatica (L.) Urban Menggunakan Metode Hidrasi Lapis Tipis. Depok: Universitas Indonesia; 2012.

13. Rasaie S, Ghanbarzadeh S, Mohammadi M, Hamishehkar H. Nano Phytosomes of quercetin: A promising formulation for fortification of 
food products with antioxidants. J Pharm Sci 2014;20(3):96-101.

14. Helal D, El-Rhman D, Abdel-Halim S, El-Nabarawi M. Formulation and evaluation of fluconazole topical gel. Int J Pharm Pharm Sci 2012;4(5):176-83.

15. Ju J, Huan ML, Wan N, Qiu H, Zhou SY, Zhang BL. Novel cholesterolbased cationic lipids as transfecting agents of DNA for efficient gene delivery. Int J Mol Sci 2015;16(3):5666-81.

16. Panwar P, Pandey B, Lakhera PC, Singh KP. Preparation, characterization, and in vitro release study of albendazole-encapsulated nanosize liposomes. Int J Nanomedicine 2010;5:101-8.

17. Meghana G, Karri VV, Talluri SV, Trivedi D, Ganesh GN. Liposomal gel for the treatment of topical fungal diseases in vitro and in vivo behavior of a carbamothioic acid. Int J ChemTech Res 2015;7(2):814-20.

18. Shaji J, Iyer S. Double-loaded liposomes encapsulating quercetin and quercetin beta-cyclodextrin complexes: Preparation, characterization and evaluation. Asian J Pharm 2012;6(3):218

19. Bhatia A, Kumar R, Katare OP. Tamoxifen in topical liposomes: Development, characterization and in-vitro evaluation. J Pharm Pharm Sci 2004;7(2):252-9.

20. Khalaf NA, ShakyaAK, Al-Othman A, El-Agbar Z, Farah H. Antioxidant activity of some common plants. Turk J Biol 2008;32(3):51-5.

21. Saadeh R, Al-Jabari M, Abdoh A, Al-Bawab A. Stability study of green tea natural extract in aqueous solutions and its chemical kinetics. Dirasat Pure Sci 2009;36(1):62-75. 